\title{
Completing the Pain Circuit: Recent Advances in Imaging Pain and Inflammation beyond the Central Nervous System
}

\author{
Clas Linnman, Ph.D.* and David Borsook, M.D., Ph.D. \\ Department of Anesthesiology, Perioperative and Pain Medicine, Boston Children's Hospital, Boston, \\ Massachusetts, United States of America
}

\begin{abstract}
This review describes some of the recent developments in imaging aspects of pain in the periphery. It is now possible to image nerves in the cornea non-invasively, to image receptor level expression and inflammatory processes in injured tissue, to image nerves and alterations in nerve properties, to image astrocyte and glial roles in neuroinflammatory processes, and to image pain conduction functionally in the trigeminal ganglion. These advances will ultimately allow us to describe the pain pathway, from injury site to behavioral consequence, in a quantitative manner. Such a development could lead to diagnostics determining the source of pain (peripheral or central), objective monitoring of treatment progression, and, hopefully, objective biomarkers of pain.
\end{abstract}

KEY WORDS: Astrocytes, inflammation, microglia, MRI, pain, PET

\begin{abstract}
Abbreviations: 3D DWPSIF, three-dimensional diffusion-weighted reversed fast imaging with steady-state precession; CCM, corneal confocal microscopy; CSF, cerebrospinal fluid; CNS, central nervous system; CRPS, complex regional pain syndrome; CT, computerized tomography; DED, deuterium-substituted deprenyl; DWI, diffusion-weighted magnetic resonance imaging; DTI, diffusion tensor imaging; ED, electrodiagnostic; FDG, fluorodeoxyglucose; FUO, fever of undetermined origin; GFAP, glial fibrillary acidic protein; MAO-B, monoamine oxidase B; MRI, magnetic resonance imaging; NK1, neurokinin-1; PET, positron emission tomography; SUV, standardized uptake value; TSPO, translocator protein.
\end{abstract}

Citation: Linnman C, Borsook D. Completing the Pain Circuit: Recent Advances in Imaging Pain and Inflammation beyond the Central Nervous System. Rambam Maimonides Med J 2013;4 (4):e0026. doi:10.5041/RMMJ.10133

Copyright: (C) 2013 Linman and Borsook. This is an open-access article. All its content, except where otherwise noted, is distributed under the terms of the Creative Commons Attribution License (http://creativecommons.org/licenses/by/3.0), which permits unrestricted use, distribution, and reproduction in any medium, provided the original work is properly cited.

Conflict of interest: No potential conflict of interest relevant to this article was reported.

* To whom correspondence should be addressed. E-mail: clas.linnman@childrens.harvard.edu 


\section{INTRODUCTION}

Early work in the fields of neuroanatomy, neurophysiology, and clinical observations has provided a robust description of pain pathways. These pathways can now be evaluated with imaging to contribute to a more objective view of pain, where both the sensory and emotional experience may be assessed in health and disease. This review describes some recent advances in imaging of pain and inflammation-related processes below the level of the brain, that is, at the level of 1) the periphery; 2) the nerve; and 3) the nerve root. We discuss methods to measure neuroinflammation and future lines of inquiry linking peripheral markers to spine, brainstem, and brain functional imaging. An ultimate goal is a more mechanistic definition than the one currently offered by the International Association for the Study of Pain: "an unpleasant sensory and emotional experience associated with actual or potential tissue damage, or described in terms of such damage."

\section{IMAGING PERIPHERAL NEUROPATHY AND INFLAMMATION}

Identifying active inflammatory pathology may be critical for adequate treatment. Further, precise measurement of inflammation may allow assessment of disease activity and assess the effect of therapeutic measures. Structural imaging methods such as computerized tomography (CT), magnetic resonance imaging (MRI), and ultrasound may detect large anatomical lesions and subtle swelling, but differentiating active disease from anatomical changes in healed tissue and/or normal variations is difficult. Two non-invasive imaging techniques, corneal confocal microscopy (CCM) and positron emission tomography (PET), may, however, provide insights into peripheral nerve function.

\section{Corneal Confocal Microscopy}

The cornea is a window into free nerve fiber endings. ${ }^{2}$ Burning neuropathic pain and small fiber sensory loss involving the limbs, trunk, and face is characterized by abnormal skin biopsies as nonlength-dependent small fiber neuropathy. A novel non-invasive technique to quantify small fiber pathology is corneal confocal microscopy (CCM). As the cornea contains $\mathrm{C}$ and A delta sensory fibers arising from branches of the trigeminal nerve, it offers a window for evaluating neuropathy in diabetic peripheral neuropathy, ${ }^{3}$ Crohn's disease, ${ }^{4}$
Sjögren's syndrome, 4 idiopathic neuropathy, 4 and Fabry's disease.5 Future studies relating CCM findings to individual variations in pain and disability and central nervous system (CNS) function are warranted.

\section{Peripheral Positron Emission Tomography}

Although it is not currently possible to image nociceptors in vivo with PET ligands directly, the technique may still inform us on the functional state of the inflammatory milieu and levels of receptor expression/occupancy. Due to changes in blood flow, vascular permeability, metabolism, white blood cell influx, and changes in the local chemical environment, many PET ligands accumulate at sites of peripheral inflammation.

Infection and inflammation may be visualized by scintigraphy and ${ }^{67}$ Gallium citrate, or autologous leukocytes labeled with indium-111 or technetium99m. ${ }^{6}$ By far the most commonly used PET ligands ${ }^{18}$ F-fluorodeoxyglucose (FDG), thanks to its availability and its excellent properties in oncological imaging. It is a tracer for glucose metabolism, and its distribution is not specific to cancer cells but is also observed in inflammatory tissue, including macrophages, capillaries, and fibroblasts. FDG has been used to image inflammation processes and treatment monitoring in rheumatoid arthritis (Figure 1a), ${ }^{7-9}$ fever of undetermined origin (FUO), focal infection, musculoskeletal infections, sarcoidosis, and vasculitis. ${ }^{10}$

We have found that the tracer ${ }^{11} \mathrm{C}-\mathrm{D}$-deprenyl provides excellent delineation of peripheral inflammatory sites, a method that holds potential to elucidate the pathophysiological mechanism in chronic musculoskeletal pain disorders, including whiplashassociated disorder (Figure $1 \mathrm{~b}$ ) ${ }^{11}$ and rheumatoid arthritis. ${ }^{12}$ The translocator protein $(18 \mathrm{kDa})$ has also been targeted to image peripheral inflammation in the lung, ${ }^{13}$ arterial walls, ${ }^{14}$ and intra-plaque inflammation in carotid atherosclerosis. ${ }^{15}$ Other peripheral inflammation probes, such as ${ }^{68} \mathrm{Ga}$ peptides targeting vascular adhesion protein 1 , are being developed (Figure 1c). ${ }^{16}$ The use of ${ }^{68} \mathrm{Ga}$ is especially interesting as the nuclide emits positrons in high yields, it is readily chelated, and it is available as a generator product rather than from a cyclotron.

The neurokinin-1 (NK1) receptor antagonist tracer ${ }^{11} \mathrm{C}-\mathrm{GR} 205171$ used for CNS imaging was recently demonstrated to show elevated unilateral 


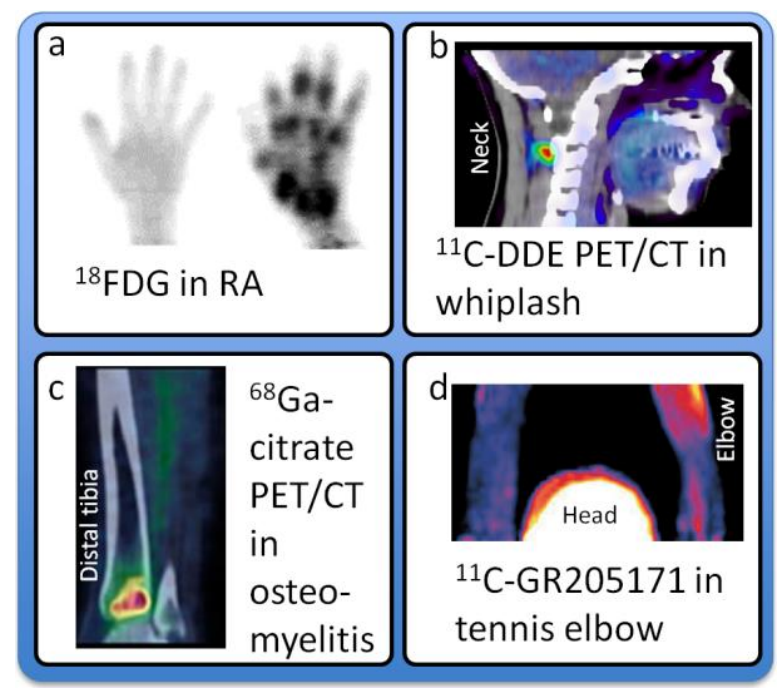

Figure 1. Examples of PET Imaging of Peripheral Pain Mechanisms.

A: ${ }^{18}$ F-FDG PET of the hand of a healthy subject and a patient with rheumatoid arthritis. Adapted from Beckers et al. ${ }^{9}$

B: ${ }^{11} \mathrm{C}$-D-deprenyl PET/CT of a patient with whiplashassociated disorder. Adapted from Linnman et al. ${ }^{11}$

C: ${ }^{68} \mathrm{Ga}$-citrate PET/CT of a patient affected by acute osteomyelitis of the left distal tibia. Adapted from Figure 6 (A ${ }^{68} \mathrm{Ga}$-citrate PET/CT scan of a patient affected by acute osteomyelitis of the left distal tibia. The scan demonstrates an area of increased tracer uptake (red area), corresponding to an area of decreased bone density on the CT images, which is consistent with acute inflammation) by Roivainen et al. ${ }^{16}$ with kind permission from Springer Science and Business Media.

D: ${ }^{11} \mathrm{C}$-GR205171 PET of a patient with unilateral chronic tennis elbow. Adapted from Peterson. ${ }^{17}$

uptake in chronic tennis elbow (Figure 1d). ${ }^{17}$ This finding suggests that NK1 receptors may be activated, or up-regulated in the peripheral, painful tissue of a chronic pain condition. The increased NK1 receptor availability is interpreted as part of ongoing neurogenic inflammation and may have correlation to the pathogenesis of chronic tennis elbow.

\section{IMAGING CENTRAL INFLAMMATION}

Glia are the most abundant cells in the nervous system, and recent research has changed the perception of glia from being just supportive cells of neurons to being dynamic partners participating in brain metabolism and communication between neurons in health and in chronic pain. ${ }^{18-21}$

Astrocytes are the most abundant brain cell type in terms of their number and volume, and they constitute $40 \%$ to $50 \%$ of all glial cells. Astrocyte reaction has been demonstrated in peripheral nerve injury and in tissue inflammation models. Peripheral chronic nerve lesion is associated with breakdown of the blood-spinal cord barrier permeability and activation of astrocytes. ${ }^{22}$ Most animal studies have focused on the role of astrocyte activation at the spinal cord dorsal horn level, but alterations can occur at supraspinal areas, such as the rostral ventromedial medulla and in the forebrain. ${ }^{23}$ The enzyme monoamine oxidase (MAO)-B exists on the outer mitochondrial membrane, occurring predominantly in astrocytes. ${ }^{24}$ When astrocytes become activated (as customarily defined by their greatly enhanced glial fibrillary acidic protein (GFAP) binding) they express high levels of $\mathrm{MAO}-\mathrm{B}, 25$ thereby providing an indirect target for PET imaging.

L-deprenyl (selegeline) is a selective irreversible MAO-B inhibitor that has been carbon-11-labeled, allowing for PET imaging of astrocyte activity. ${ }^{26} \mathrm{~A}$ deuterium substitution on the L-deprenyl molecule causes a significant reduction in the rate of trapping, thereby further enhancing the tracer's sensitivity to subtle changes in MAO-B concentration. ${ }^{27}$ Thus far, studies using this deuterium-substituted deprenyl (DED) tracer have been performed to assess MAO-B function and astrocytosis in epilepsy, ${ }^{28}$ amyotrophic lateral sclerosis, ${ }^{29}$ Creutzfeldt-Jakob disease, ${ }^{30}$ and Alzheimer's disease. $3^{1}$ No study to date has utilized MAO-B expression to image spinal cord or brain astrocyte involvement in human pain.

Microglia are the resident macrophages of the brain and spinal cord and thus act as the first and main form of active immune defense in the central nervous system. Microglia rapidly activate in response to a variety of pathological conditions, including nerve damage and persistent pain. ${ }^{20}$ Microglial activation is characterized by cellular responses including specific morphological changes, proliferation, increased or de novo expression of cell surface markers or receptors, and migration to the site of injury. ${ }^{32}$ Activated microglia express translocator protein (TSPO), which has been observed in animal models of neuropathic pain both in the dorsal horns of the spinal cord, 33 the spine, 34 and in cortex.35 In human studies, increased TSPO 
expression has been reported in the thalamus after peripheral nerve injuries ${ }^{36}$ and in widespread cortical regions after traumatic brain injury. 37 PRB28, a second-generation, high-affinity TSPO radioligand suitable for imaging of microglial activation in neuroinflammation, 38 is currently being explored for pain imaging.

MAO-B expression occurs primarily in astrocytes, while TSPO expression occurs in activated microglia and to a lesser degree in active astrocytes. Compared with the microglial response to nerve injury, astrocyte proliferation begins relatively late and progresses slowly but is sustained for more than 5 months, a time-frame paralleling the development of chronic pain. 39 Unlike microglia, astrocytes form networks with themselves and are closely associated with neurons and blood vessels, a close contact that makes it possible for astrocytes to regulate the external chemical environment of neurons during synaptic transmission. Moreover, there is recent evidence that spinal astrocytes but not microglia contribute to the pathogenesis of painful neuropathy. 39 Thus, the astrocyte and microglial systems are somewhat orthogonal, and site-specific PET probes may be used indicate different pathological mechanisms.

\section{IMAGING NERVES IN PAIN}

High-resolution magnetic resonance neurography provides excellent visualization of peripheral nerves and may be an integral component in evaluating nerve injuries, supplementing electrodiagnostic (ED) studies, such as electromyography, nerve conduction studies, and quantitative neurosensory testing. ${ }^{40}$ Structural imaging of nerve bundles, however, has been optimized to provide 3-dimensional high-resolution and high-contrast neurography. Diffusion-weighted magnetic resonance imaging (DWI) demonstrates the random diffusion of water. By evaluating water diffusion in multiple directions, nerve fiber tracts, with their myelin sheath, may be visualized though tractography, as water diffuses along but not across the nerve bundles. 41

Functional imaging of the nerves and nerve roots has, to the best of our knowledge, not yet been achieved. The utility of structural and diffusion imaging of neuropathies is illustrated by a collection of prominent studies, ${ }^{42-45}$ reproduced in Figure 2.

\section{IMAGING NERVE ROOTS IN PAIN}

Primary afferent nerves in the dorsal root ganglia convey pain information to the central nervous system. Both peripheral inflammation and nerve damage can lead to alterations in anatomy and function of neurons within the ganglion, alterations that contribute to persistent pain states.46,47 While the dorsal roots are too small for standard neuroimaging approaches, the trigeminal ganglion serves an equivalent role for the trigeminal nerve. The trigeminal ganglion is located at the base of the brain in the posterior cranial fossa across the superior border of the petrous temporal bone. It comprises sensory neurons from the ophthalmic (V1), maxillary (V2), and mandibular (V3) divisions of the trigeminal nerve. We have demonstrated that fMRI can be used to assess both sensory (brush) and noxious thermal activation of the ganglion. Activation occurred ipsilaterally and somatotopically, as predicted by the known anatomical segregation of the neurons comprising the $\mathrm{V}_{1}, \mathrm{~V}_{2}$, and $\mathrm{V}_{3}$ divisions of the nerve (Figure 3). $4^{6}$ We have further demonstrated that sensory processing in patients with trigeminal neuropathic pain is associated with distinct activation patterns consistent with sensitization within and outside of the primary sensory pathway, 48 and, in a case study, we demonstrated trigeminal ganglion activation in photophobia. 49 Using diffusion tensor imaging, we have further been able to segment the peripheral trigeminal circuitry, trigeminal nerve branches (ophthalmic, maxillary, and mandibular nerves), ganglion, and nerve root, and further segment the spinal trigeminal and trigeminal thalamic tracts, which, respectively, convey information to the spinal trigeminal nuclei and ventral thalamic regions.50 Moreover, we have demonstrated a direct pathway from the optic nerve to the pulvinar nuclei in the posterior thalamus, providing a possible mechanism for exacerbation of pain by light in migraine. ${ }^{11}$ Other groups have demonstrated alterations in trigeminal nerve diffusion in trigeminal neuralgia ${ }^{2-55}$ and in temporomandibular disorder. $5^{6}$

Taken together, these studies demonstrate that, at least for cranial nerves, functional and diffusion MRI can provide mechanistic insight into pain processes at the interphase of the peripheral and central nervous system. 
Figure 2. Examples of MRI Nerve Imaging.

a: Tractography of the median nerve in carpal tunnel syndrome, where patients displayed a significant decrease in median nerve fractional anisotropy. Taken from Figure 2 (Tractography image demonstrating the median nerve, coded in blue, with an excellent correlation, with the reference T1weighted image in a patient suffering from carpal tunnel syndrome) of Khalil et al. $^{44}$ with kind permission from Springer Science and Business Media.

b: Three-dimensional diffusion-weighted reversed fast imaging with steady-state precession (3D DWPSIF) of enlarged plantar nerves in a patient with entrapments following a repeat tarsal tunnel surgery. Taken from Figure 5b (A 32-year-old female with medial and lateral plantar nerve entrapments following a repeat tarsal tunnel surgery ... Notice the depiction of the enlarged plantar nerves on the 3D DW-PSIF image) of Chhabra et al. ${ }^{42}$ with kind permission from Springer Science and Business Media.

c: Lumbar nerve roots in a healthy subject and a patient with right L1-S1 foraminal stenosis, indicative of nerve root entrapment. Taken from Eguchi et al. ${ }^{43}$ with permission of the American Society of Neuroradiology.

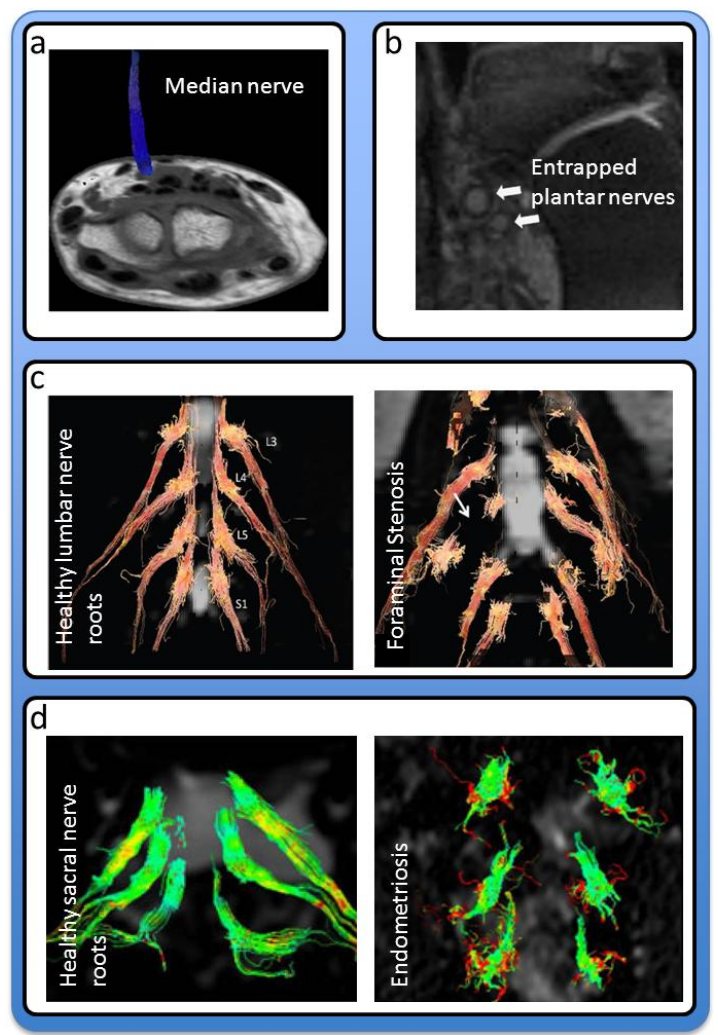

d: Fiber tracking reconstruction in a healthy woman and a patient with widespread endometriosis. Taken from Figures 2 and 3 (2: Example of fibre tracking reconstruction in a healthy woman showing S1, S2 and S3 nerve roots. Images are displayed in the coronal planes (radiological convention). Fibre bundles S1 to S3 display a homogeneous appearance and regular course bilaterally. 3: Fibre tracking reconstruction in a woman affected by endometriosis of the medium and posterior compartment. The fibre bundles are short, stubby and have lots of branches.) of Manganaro et al. ${ }^{45}$ with kind permission from Springer Science and Business Media.

\section{SPINAL CORD PAIN IMAGING}

\section{Positron Emission Tomography (PET)}

The metabolic rate of glucose increases in the spinal cord during nociceptive in-flow, 57,58 affording a mechanism to image spinal pain signaling using ${ }^{18} \mathrm{~F}$-fluorodeoxyglucose. We found no studies demonstrating altered spinal PET ligand uptake in pain, but such an endeavor appears possible if there is massive peripheral signaling. FDG is routinely used in oncological staging, and a retrospective analysis of cancer pain patients might demonstrate elevated FDG uptake in corresponding segments of the spinal cord. Ideally, such a study would utilize high-resolution PET in combination with MR or CT to delineate the spinal cord cross-section in multiple voxels, allowing assessment of anterior and posterior segments, and possibly lateralization effects. To illustrate PET imaging of the spine, we present mean FDG standardized uptake values (SUV) obtained from two studies of 92 patients59 and 30 patients ${ }^{60}$ without spinal malignancy (Figure 4).

\section{Magnetic Resonance Imaging}

Structural MRI is used routinely to assess spinal cord injuries, but due to the spine's small crosssection, and noise sources such as motion, cerebrospinal fluid (CSF) pulsation, and magnetic susceptibility, functional imaging of the spine is technically challenging. Recent developments in MR sequences and post-processing have opened up the field, and it is possible to define structure and function with greater specificity. ${ }^{61}$ The first functional spinal cord imaging results were published in 1999, indicating that 3 -tesla imaging of the cervical spinal cord showed that repeated hand exercise led to a blood-oxygenation level dependent (BOLD)-like increase in spinal cord signal, predominantly on the ipsilateral spinal cord between $\mathrm{C} 6$ and T1. ${ }^{62}$ Since then, spinal fMRI has 


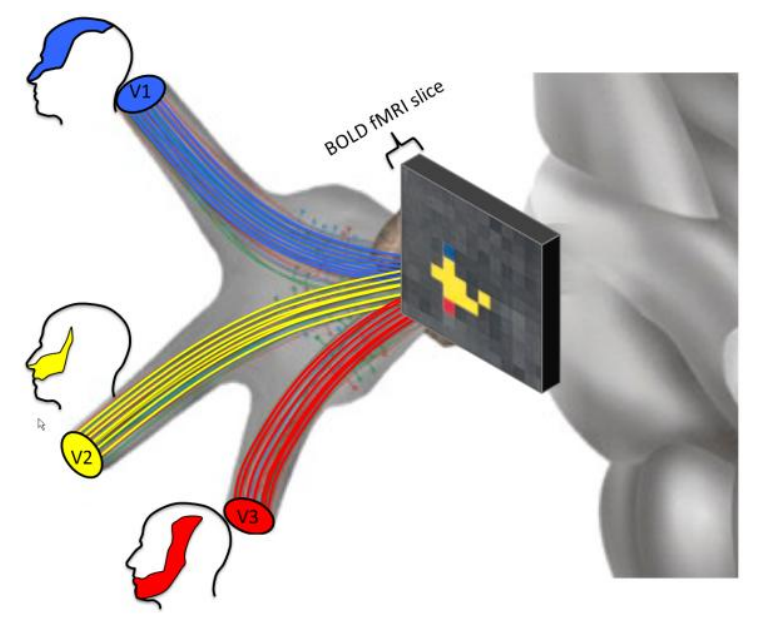

Figure 3. Somatotopically Organized Activation Patterns of the Human Trigeminal Ganglion Evoked by Noxious Heat to the Ophthalmic (V1), Maxillary (V2), and Mandibular (V3) Facial Regions.

Adapted with permission from Borsook et al. ${ }^{46}$

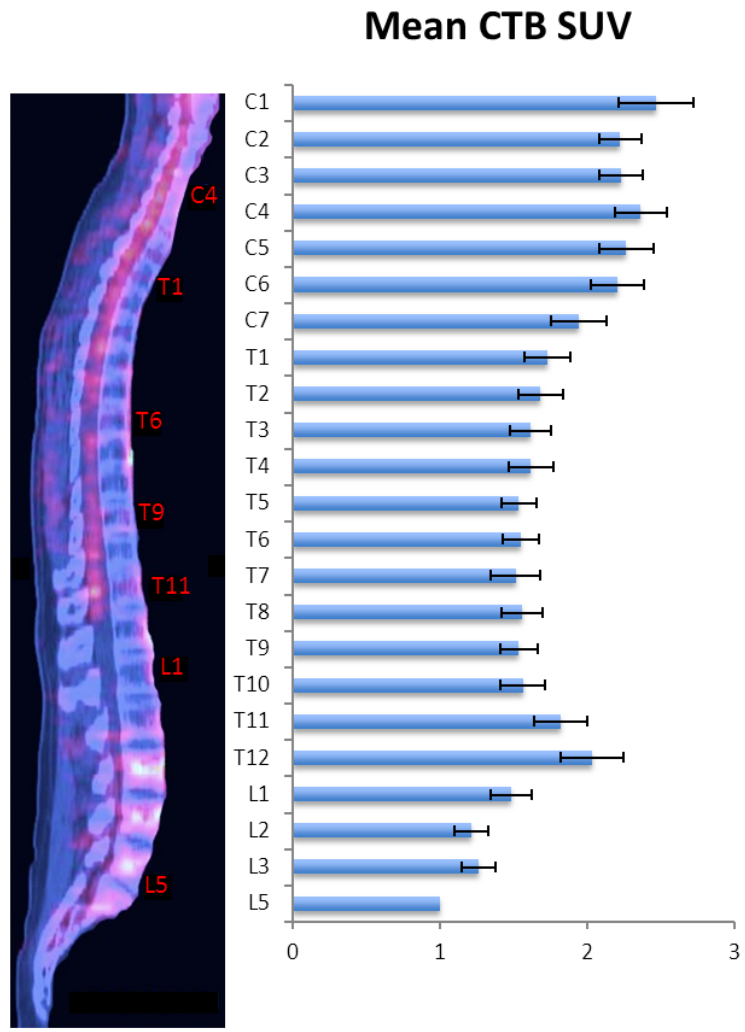

Figure 4. Midline ${ }^{18} \mathrm{~F}$-FDG PET/CT of a Healthy Spinal Cord.

Bar plot illustrates weighted mean cord-to-background (CTB) ratio from 122 patients. ${ }^{59,60}$ been reported using multiple paradigms (pain, motor, vibration, light touch) in healthy subjects and in patient populations including carpal tunnel syndrome, spinal cord injuries, and multiple sclerosis. These studies, along with methodological advances, are the subject of two excellent reviews on state-of-the-art spinal cord imaging methods ${ }^{63}$ and applications ${ }^{64}$ that we refer the reader to for full details.

\section{COMPLETING THE PAIN CIRCUIT: CENTRAL NETWORKS}

There are only a handful of studies that have attempted to relate peripheral alterations to CNS dysfunction. An excellent example of such an approach is determining the relationship between carpal tunnel nerve conduction velocity and regional gray matter alterations in the brain. 65 This study found that patients with carpal tunnel syndrome had significant gray matter reductions in the hand area of the somatosensory cortex, a reduction that was correlated to lower median nerve conduction velocity. Of note, diffusion tensor imaging (DTI) of the medial nerve pre and post carpal tunnel surgery indicates that postoperative clinical improvement is related to nerve diffusivity but not anisotropy. ${ }^{66} \mathrm{~A}$ next step may be to combine peripheral MR neurography with CNS imaging of brain morphology and function to evaluate how and when the periphery and CNS are affected by treatment. Another recent example used a combined analyte, behavioral, and imaging assessment of a rat sciatic nerve injury model to provide a "pathophysiological signature"; results indicate that the nerve injury was reflected in peripheral and central soft tissues, as well as in the expression of circulating cytokines, chemokines, and growth factors. ${ }^{67}$

Functional MRI and machine-learning pattern recognition can be used to define neurologic signature of acute pain with high sensitivity and specificity ${ }^{68}$ The hardware (3T MRI, PET, and PETMR), scanning sequences (structural, diffusion, BOLD, and spectroscopy), and analytical software now available have allowed the research community to quantify several aspects of the pain circuit, ${ }^{69-75}$ as illustrated in Figure 5. This circuitry is further linked to behavioral and psychological measures of pain experience, pain-related behaviors, and paininduced co-morbidities and risk factors such as catastrophizing, fear of movement, and depression. The levels of inquiry range from genetic via 


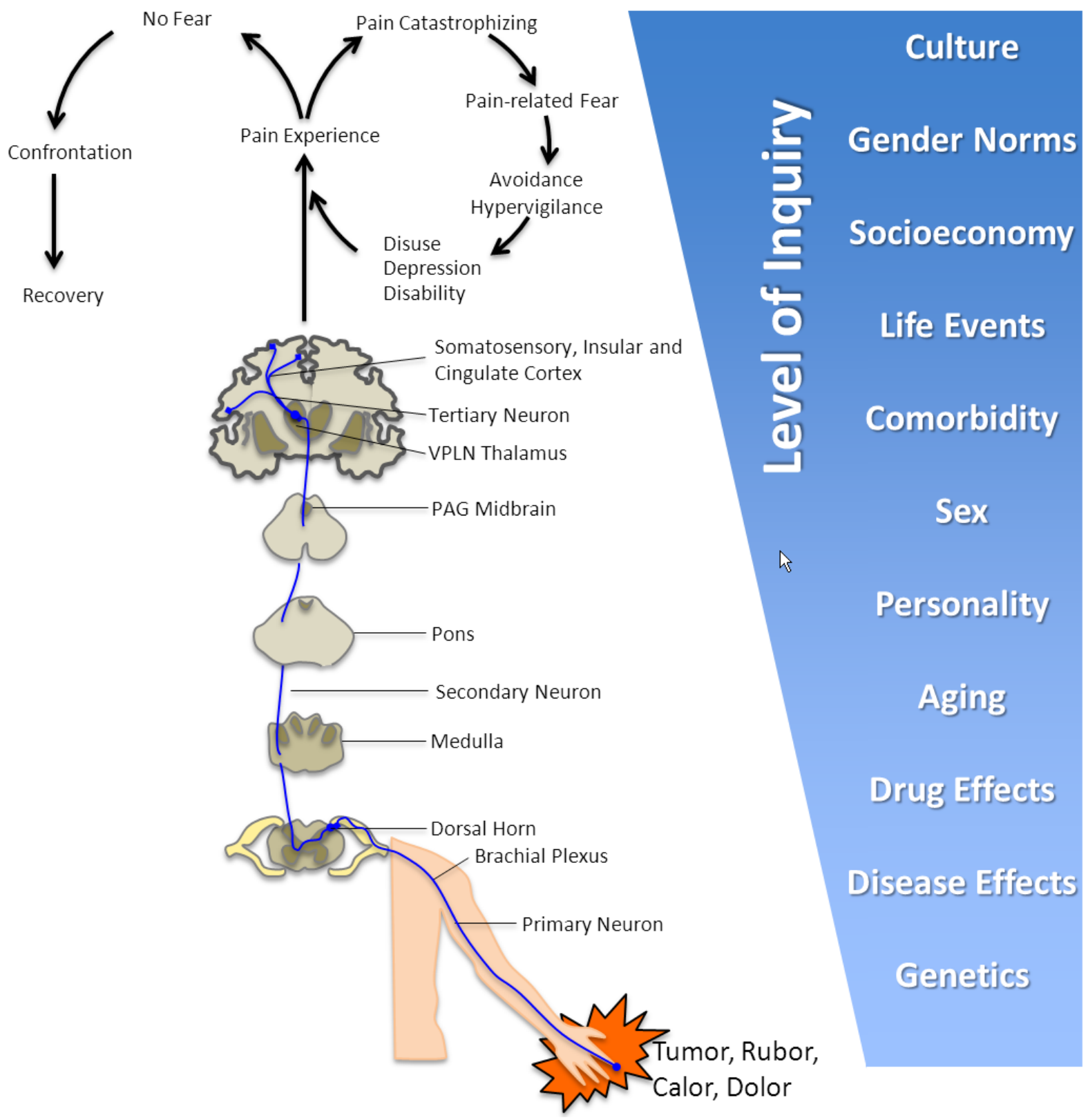

Figure 5. An Illustration of the Levels of Inquiry in Pain Behavior That Imaging Has the Possibility to Inform Upon.

The Fear-Avoidance Model is an adaptation from Vlaeyen et al. and Lethem et al. ${ }^{69,70}$ Notably, inflammatory processes may interact at several levels of the pain behavior circuit. For example, the catechol-0-methyltransferase (COMT) val158met polymorphism may influence the neuronal ${ }^{71}$ and opioidergic ${ }^{72}$ response to pain (but see also Nicholl et al. ${ }^{73}$ ). Furthermore, the 18-kDa translocator protein (TSPO) Ala147Thr genotype asserts a strong influence on the binding affinity of microglial PET tracers ${ }^{74}$ and thus needs to be accounted for in between subject analyses. At the other end of the spectrum, imaging studies are beginning to explore how culture may interact with brain processing of perception and emotional valuation. ${ }^{75}$ 
neurophysiological to psychological and even sociological and anthropological domains (i.e. the perception, expression, and tolerance of pain are influenced by a variety of non-biological processes, such as disparities in work, economy, daily living, social life, gender norms, and cultural setting76-78).

Clearly, the study of pain is and will remain a multidisciplinary field. Animal imaging of brain systems, reviewed by Borsook and Becerra, 79 offers the possibility of imaging awake animals and may serve as a "language of translation" between preclinical to clinical models. Human imaging, in turn, has strengthened and made objective the links between CNS neurophysiology and psychology of pain modulation. We foresee a similar development in the field of peripheral inflammation and spine imaging.

\section{FUTURE DIRECTIONS}

An increasing body of literature has implicated inflammation as a contributor to the initiation but also to the maintenance of chronic pain, whether it be an obvious inflammatory process produced by specific disease (e.g. rheumatoid arthritis, chronic pancreatitis), following trauma (e.g. post-surgical neuroinflammation), or other neuropathic conditions such as complex regional pain syndrome (CRPS). It seems increasingly clear that peripheral inflammation may produce central inflammatory processes. ${ }^{80-85}$ In addition, central inflammationeven in brain areas rarely considered to be involved in chronic pain, for example in the hippocampusproduce neuropathic-like behavior in rats. ${ }^{86}$ In humans such changes in brain neuroinflammation contribute to altered pain ${ }^{87}$ and mood changes. 88,89 Thus, the ability to measure neuroinflammation in humans with pain in both the peripheral and central nervous systems may provide objective indices for: 1) ongoing inflammation that may produce the maintenance of the disease either in the periphery ${ }^{83}$ or centrally;36 and 2) objective measures for treatment effects. While imaging markers may provide an initial definition of the status of inflammation, blood or serum markers may eventually be more sensitive and provide a more cost-effective use in the clinic.

\section{REFERENCES}

1. Merskey H, Bogduk N, International Association for the Study of Pain. Task Force on Taxonomy. Classification of Chronic Pain: Descriptions of
Chronic Pain Syndromes and Definitions of Pain Terms. 2nd ed. IASP Press Seattle;1994.

2. Rosenthal P, Borsook D. The corneal pain system. Part I: the missing piece of the dry eye puzzle. Ocul Surf 2012;10:2-14. Full Text

3. Shahidi AM, Sampson GP, Pritchard N, et al. Exploring retinal and functional markers of diabetic neuropathy. Clin Exp Optom 2010;93:309-23. Full Text

4. Gemignani F, Ferrari G, Vitetta F, Giovanelli M, Macaluso C, Marbini A. Non-length-dependent small fibre neuropathy. Confocal microscopy study of the corneal innervation. J Neurol Neurosurg Psychiatry 2010;81:731-3. Full Text

5. Tavakoli M, Marshall A, Thompson L, et al. Corneal confocal microscopy: a novel noninvasive means to diagnose neuropathy in patients with Fabry disease. Muscle Nerve 2009;40:976-84. Full Text

6. Rennen HJ, Boerman OC, Oyen WJ, Corstens FH. Imaging infection/inflammation in the new millennium. Eur J Nucl Med 2001;28:241-52. Full Text

7. Chaudhari AJ, Bowen SL, Burkett GW, et al. Highresolution (18)F-FDG PET with MRI for monitoring response to treatment in rheumatoid arthritis. Eur $\mathbf{J}$ Nucl Med Mol Imaging 2010;37:1047. Full Text

8. Kubota K, Ito K, Morooka M, et al. FDG PET for rheumatoid arthritis: basic considerations and wholebody PET/CT. Ann N Y Acad Sci 2011;1228:29-38. Full Text

9. Beckers C, Ribbens C, Andre B, et al. Assessment of disease activity in rheumatoid arthritis with (18)FFDG PET. J Nucl Med 2004;45(6):956-64.

10. Love C, Tomas MB, Tronco GG, Palestro CJ. FDG PET of infection and inflammation. Radiographics 2005;25:1357-68. Full Text

11. Linnman C, Appel L, Fredrikson M, et al. Elevated [11C]-D-deprenyl uptake in chronic Whiplash Associated Disorder suggests persistent musculoskeletal inflammation. PLoS One 2011;6:e19182. Full Text

12. Danfors T, Bergstrom M, Feltelius N, Ahlstrom H, Westerberg G, Langstrom B. Positron emission tomography with 11C-D-deprenyl in patients with rheumatoid arthritis. Evaluation of knee joint inflammation before and after intra-articular glucocorticoid treatment. Scand J Rheumatol 1997;26:43-8. Full Text

13. Hatori A, Yui J, Yamasaki T, et al. PET imaging of lung inflammation with [(18)F]FEDAC, a radioligand for translocator protein $(18 \mathrm{kDa})$. PLoS One. 2012;7:e45065. Full Text

14. Lamare F, Hinz R, Gaemperli O, et al. Detection and quantification of large-vessel inflammation with 11C- 
(R)-PK11195 PET/CT. J Nucl Med 2011;52:33-9. Full $\underline{\text { Text }}$

15. Gaemperli O, Shalhoub J, Owen DR, et al. Imaging intraplaque inflammation in carotid atherosclerosis with 11C-PK11195 positron emission tomography/computed tomography. Eur Heart J 2012;33:1902-10. Full Text

16. Roivainen A, Jalkanen S, Nanni C. Gallium-labelled peptides for imaging of inflammation. Eur $\mathrm{J}$ Nucl Med Mol Imaging 2012;39(Suppl 1):S68-77. Full Text

17. Peterson M. Chronic Tennis Elbow: Aspects on Pathogenesis and Treatment in a Soft Tissue Pain Condition. Uppsala: Uppsala University; 2011.

18. Linnman C, Becerra L, Borsook D. Inflaming the brain: CRPS a model disease to understand neuroimmune interactions in chronic pain. J Neuroimmune Pharmacol 2013;8:547-63. Full Text

19. Austin PJ, Moalem-Taylor G. The neuro-immune balance in neuropathic pain: involvement of inflammatory immune cells, immune-like glial cells and cytokines. J Neuroimmunol 2010;229:26-50. Full Text

20. Milligan ED, Watkins LR. Pathological and protective roles of glia in chronic pain. Nat Rev Neurosci 2009;10:23-36. Full Text

21. Watkins LR, Milligan ED, Maier SF. Glial activation: a driving force for pathological pain. Trends Neurosci 2001;24:450-5. Full Text

22. Gordh T, Chu H, Sharma HS. Spinal nerve lesion alters blood-spinal cord barrier function and activates astrocytes in the rat. Pain 2006;124:211-21. Full Text

23. Raghavendra V, Tanga FY, DeLeo JA. Complete Freunds adjuvant-induced peripheral inflammation evokes glial activation and proinflammatory cytokine expression in the CNS. Eur J Neurosci 2004;20:46773. Full Text

24. Fowler JS, Logan J, Volkow ND, Wang GJ. Translational neuroimaging: positron emission tomography studies of monoamine oxidase. Mol Imaging Biol. 2005;7:377-87. Full Text

25. Ekblom J, Jossan SS, Bergstrom M, Oreland L, Walum E, Aquilonius SM. Monoamine oxidase-B in astrocytes. Glia 1993;8:122-32. Full Text

26. Fowler JS, MacGregor RR, Wolf AP, et al. Mapping human brain monoamine oxidase A and B with $11 \mathrm{C}$ labeled suicide inactivators and PET. Science 1987;235:481-5. Full Text

27. Fowler JS, Wang GJ, Logan J, et al. Selective reduction of radiotracer trapping by deuterium sub- stitution: comparison of carbon-11-L-deprenyl and carbon-11-deprenyl-D2 for MAO B mapping. J Nucl Med 1995;36:1255-62.

28. Kumlien E, Nilsson A, Hagberg G, Langstrom B, Bergstrom M. PET with 11C-deuterium-deprenyl and 18F-FDG in focal epilepsy. Acta Neurol Scand 2001;103:360-6. Full Text

29. Johansson A, Engler H, Blomquist G, et al. Evidence for astrocytosis in ALS demonstrated by [11C](L)deprenyl-D2 PET. J Neurol Sci 2007;255:17-22. Full Text

30. Engler H, Nennesmo I, Kumlien E, et al. Imaging astrocytosis with PET in Creutzfeldt-Jakob disease: case report with histopathological findings. Int $\mathrm{J}$ Clin Exp Med 2012;5:201-7.

31. Santillo AF, Gambini JP, Lannfelt L, et al. In vivo imaging of astrocytosis in Alzheimer's disease: an (1)(1)C-L-deuteriodeprenyl and PIB PET study. Eur J Nucl Med Mol Imaging 2011;38:2202-8. Full Text

32. Gehrmann J, Matsumoto Y, Kreutzberg GW. Microglia: intrinsic immuneffector cell of the brain. Brain Res Brain Res Rev 1995;20:269-87. Full Text

33. Karchewski LA, Bloechlinger S, Woolf CJ. Axonal injury-dependent induction of the peripheral benzodiazepine receptor in small-diameter adult rat primary sensory neurons. Eur $J$ Neurosci 2004;20:671-83. Full Text

34. Imamoto $N$, Momosaki $S$, Fujita $M$, et al. [11C]PK11195 PET imaging of spinal glial activation after nerve injury in rats. Neuroimage 2013;79:121-8. Full Text

35. Cui Y, Takashima T, Takashima-Hirano M, et al. 11CPK11195 PET for the in vivo evaluation of neuroinflammation in the rat brain after cortical spreading depression. J Nucl Med 2009;50:1904-11. Full Text

36. Banati RB, Cagnin A, Brooks DJ, et al. Long-term trans-synaptic glial responses in the human thalamus after peripheral nerve injury. Neuroreport 2001;12:3439-42. Full Text

37. Folkersma H, Boellaard R, Yaqub M, et al. Widespread and prolonged increase in (R)-(11)C-PK11195 binding after traumatic brain injury. $J$ Nucl Med 2011;52:1235-9. Full Text

38. Kreisl WC, Fujita M, Fujimura Y, et al. Comparison of [(11)C]-(R)-PK 11195 and [(11)C]PBR28, two radioligands for translocator protein $(18 \mathrm{kDa})$ in human and monkey: implications for positron emission tomographic imaging of this inflammation biomarker. Neuroimage 2010;49:2924-32. Full Text

39. Zhang H, Yoon SY, Zhang H, Dougherty PM. Evidence that spinal astrocytes but not microglia contribute to the pathogenesis of paclitaxel-induced 
painful neuropathy. J Pain 2012;13:293-303. Full $\underline{\text { Text }}$

40. Chhabra A, Lee PP, Bizzell C, Soldatos T. 3 Tesla MR neurography--technique, interpretation, and pitfalls. Skeletal Radiol 2011;40:1249-6o. Full Text

41. Jambawalikar S, Baum J, Button T, Li H, Geronimo $\mathrm{V}$, Gould ES. Diffusion tensor imaging of peripheral nerves. Skeletal Radiol 2010;39:1073-9. Full Text

42. Chhabra A, Subhawong TK, Bizzell C, Flammang A, Soldatos T. 3T MR neurography using threedimensional diffusion-weighted PSIF: technical issues and advantages. Skeletal Radiol 2011;40:135560. Full Text

43. Eguchi Y, Ohtori S, Orita S, et al. Quantitative evaluation and visualization of lumbar foraminal nerve root entrapment by using diffusion tensor imaging: preliminary results. AJNR Am J Neuroradiol 2011;32:1824-9. Full Text

44. Khalil C, Hancart C, Le Thuc V, Chantelot C, Chechin D, Cotten A. Diffusion tensor imaging and tractography of the median nerve in carpal tunnel syndrome: preliminary results. Eur Radiol 2008;18:2283-91. Full Text

45. Manganaro L, Porpora MG, Vinci V, et al. Diffusion tensor imaging and tractography to evaluate sacral nerve root abnormalities in endometriosis-related pain: a pilot study. Eur Radiol 2013 Aug 28. [Epub ahead of print] Full Text

46. Borsook D, DaSilva AF, Ploghaus A, Becerra L. Specific and somatotopic functional magnetic resonance imaging activation in the trigeminal ganglion by brush and noxious heat. $J$ Neurosci 2003;23:7897-903.

47. Woolf CJ, Salter MW. Neuronal plasticity: increasing the gain in pain. Science 2000;288:1765-9. Full Text

48. Becerra L, Morris S, Bazes S, et al. Trigeminal neuropathic pain alters responses in CNS circuits to mechanical (brush) and thermal (cold and heat) stimuli. J Neurosci 2006;26:10646-57. Full Text

49. Moulton EA, Becerra L, Borsook D. An fMRI case report of photophobia: activation of the trigeminal nociceptive pathway. Pain 2009;145:358-63. Full Text

50. Upadhyay J, Knudsen J, Anderson J, Becerra L, Borsook D. Noninvasive mapping of human trigeminal brainstem pathways. Magn Reson 2008;60:1037-46. Full Text

51. Maleki N, Becerra L, Upadhyay J, Burstein R, Borsook D. Direct optic nerve pulvinar connections defined by diffusion MR tractography in humans: implications for photophobia. Hum Brain Mapp 2012;33:75-88. Full Text

52. Desouza DD, Hodaie M, Davis KD. Abnormal trigeminal nerve microstructure and brain white matter in idiopathic trigeminal neuralgia. Pain 2013 Aug 30. [Epub ahead of print] Full Text

53. Lutz J, Linn J, Mehrkens JH, et al. Trigeminal neuralgia due to neurovascular compression: highspatial-resolution diffusion-tensor imaging reveals microstructural neural changes. Radiology 2011;258:524-30. Full Text

54. Leal PR, Roch JA, Hermier M, Souza MA, CristinoFilho G, Sindou M. Structural abnormalities of the trigeminal root revealed by diffusion tensor imaging in patients with trigeminal neuralgia caused by neurovascular compression: a prospective, doubleblind, controlled study. Pain 2011;152:2357-64. Full $\underline{\text { Text }}$

55. Herweh C, Kress B, Rasche D, et al. Loss of anisotropy in trigeminal neuralgia revealed by diffusion tensor imaging. Neurology 2007;68:776-8. Full Text

56. Moayedi M, Weissman-Fogel I, Salomons TV, et al. White matter brain and trigeminal nerve abnormalities in temporomandibular disorder. Pain 2012;153:1467-77. Full Text

57. Coghill RC, Price DD, Hayes RL, Mayer DJ. Spatial distribution of nociceptive processing in the rat spinal cord. J Neurophysiol 1991;65:133-40.

58. Porro CA, Cavazzuti M, Galetti A, Sassatelli L, Barbieri GC. Functional activity mapping of the rat spinal cord during formalin-induced noxious stimulation. Neuroscience 1991;41:655-65. Full Text

59. Do BH, Mari C, Tseng JR, Quon A, Rosenberg J, Biswal S. Pattern of 18 F-FDG uptake in the spinal cord in patients with non-central nervous system malignancy. Spine 2011;36:E1395-401. Full Text

6o. Chong A, Song HC, Byun BH, et al. Changes in (18)ffluorodeoxyglucose uptake in the spinal cord in a healthy population on serial positron emission tomography/computed tomography. Chonnam Med J 2013;49:38-42. Full Text

61. Smith SA, Pekar JJ, van Zijl PC. Advanced MRI strategies for assessing spinal cord injury. Handb Clin Neurol 2012;109:85-101. Full Text

62. Stroman PW, Nance PW, Ryner LN. BOLD MRI of the human cervical spinal cord at 3 tesla. Magn Reson Med 1999;42:571-6. Full Text

63. Stroman PW, Wheeler-Kingshott C, Bacon M, et al. The current state-of-the-art of spinal cord imaging: methods. Neuroimage 2013 May 14. [Epub ahead of print] Full Text 
64. Wheeler-Kingshott CA, Stroman PW, Schwab JM, et al. The current state-of-the-art of spinal cord imaging: applications. Neuroimage 2013 Jul 14. [Epub ahead of print]

65. Lasko L, Huang X, Voorbach MJ, et al. Multimodal assessment of nervous and immune system responses following sciatic nerve injury. Pain 2013 Aug 21. [Epub ahead of print]

66. Loggia ML, Jensen K, Gollub RL, Wasan AD, Edwards RR, Kong J. The catechol-O-methyltransferase (COMT) val158met polymorphism affects brain responses to repeated painful stimuli. PLoS One. 2011;6:e27764.

67. Good MJD, Brodwin PE, Good BJ, Kleinman A. Pain as a Human Experience: An Antropological Perspective. Berkeley: University of California Press; 1992.

68. Maeda Y, Kettner N, Sheehan J, et al. Altered brain morphometry in carpal tunnel syndrome is associated with median nerve pathology. Neuroimage (Amst). 2013;2:313-19. Full Text

69. Hiltunen J, Kirveskari E, Numminen J, Lindfors N, Goransson H, Hari R. Pre- and post-operative diffusion tensor imaging of the median nerve in carpal tunnel syndrome. Eur Radiol 2012;22:1310-19. Full Text

70. Wager TD, Atlas LY, Lindquist MA, Roy M, Woo CW, Kross E. An fMRI-based neurologic signature of physical pain. N Engl J Med 2013;368:1388-97. Full $\underline{\text { Text }}$

71. Vlaeyen JW, Linton SJ. Fear-avoidance and its consequences in chronic musculoskeletal pain: a state of the art. Pain 2000;85:317-32. Full Text

72. Lethem J, Slade PD, Troup JD, Bentley G. Outline of a Fear-Avoidance Model of exaggerated pain perception--I. Behav Res Ther 1983;21:401-8. Full Text

73. Zubieta JK, Heitzeg MM, Smith YR, et al. COMT val158met genotype affects mu-opioid neurotransmitter responses to a pain stressor. Science 2003; 299:1240-3. Full Text

74. Nicholl BI, Holliday KL, Macfarlane GJ, et al. No evidence for a role of the catechol-O-methyltransferase pain sensitivity haplotypes in chronic widespread pain. Ann Rheum Dis 2010;69:2009-12. Full Text

75. Owen DR, Yeo AJ, Gunn RN, et al. An 18-kDa translocator protein (TSPO) polymorphism explains differences in binding affinity of the PET radioligand PBR28. J Cereb Blood Flow Metab 2012;32:1-5. Full $\underline{\text { Text }}$

76. Han S, Northoff G. Culture-sensitive neural substrates of human cognition: a transcultural neuro- imaging approach. Nat Rev Neurosci. 2008;9:64654. Full Text

77. Bingefors K, Isacson D. Epidemiology, co-morbidity, and impact on health-related quality of life of selfreported headache and musculoskeletal pain--a gender perspective. Eur J pain 2004;8:435-50. Full Text

78. Myers CD, Riley JL, 3rd, Robinson ME. Psychosocial contributions to sex-correlated differences in pain. Clin J Pain 2003;19:225-32. Full Text

79. Borsook D, Becerra L. CNS animal fMRI in pain and analgesia. Neurosci Biobehav Rev 2011;35:1125-43. Full Text

80. Costigan M, Moss A, Latremoliere A, et al. T-cell infiltration and signaling in the adult dorsal spinal cord is a major contributor to neuropathic pain-like hypersensitivity. J Neurosci 2009;29:14415-22. Full Text

81. Gao YJ, Ji RR. Chemokines, neuronal-glial interactions, and central processing of neuropathic pain. Pharmacol Ther 2010;126:56-68. Full Text

82. Ellis A, Bennett DL. Neuroinflammation and the generation of neuropathic pain. $\mathrm{Br} \mathrm{J}$ Anaesth 2013;111:26-37. Full Text

83. Lenz M, Uceyler N, Frettloh J, et al. Local cytokine changes in complex regional pain syndrome type I (CRPS I) resolve after 6 months. Pain 2013;154:2142-9. Full Text

84. Ramesh G, Maclean AG, Philipp MT. Cytokines and chemokines at the crossroads of neuroinflammation, neurodegeneration, and neuropathic pain. Mediators Inflamm 2013;2013:480739. Full Text

85. Hauser J, Hsu B, Nader ND. Inflammatory processes in complex regional pain syndromes. Immunol Invest. 2013;42:263-72. Full Text

86. Martuscello RT, Spengler RN, Bonoiu AC, et al. Increasing TNF levels solely in the rat hippocampus produces persistent pain-like symptoms. Pain 2012;153:1871-82. Full Text

87. Benson S, Engler H, Schedlowski M, Elsenbruch S. Experimental endotoxemia as a model to study neuroimmune mechanisms in human visceral pain. Ann N Y Acad Sci 2012;1262:108-17. Full Text

88. Grigoleit JS, Kullmann JS, Wolf OT, et al. Dosedependent effects of endotoxin on neurobehavioral functions in humans. PLoS One. 2011;6:e28330.

89. Harrison NA, Brydon L, Walker C, Gray MA, Steptoe A, Critchley HD. Inflammation causes mood changes through alterations in subgenual cingulate activity and mesolimbic connectivity. Biol Psychiatry 2009;66:407-14. Full Text 